Research Article

\title{
Impact Behavior of a Laterally Loaded Guardrail Post near Slopes by Hybrid SPH Model
}

\author{
Kwang S. Woo, ${ }^{1}$ Dong W. Lee, ${ }^{1}$ and Jae S. Ahn $\mathbb{D}^{2}$ \\ ${ }^{1}$ Department of Civil Engineering, Yeungnam University, 280 Daehak-Ro, Gyeongsan, Gyeongbuk 38541, Republic of Korea \\ ${ }^{2}$ School of General Education, Yeungnam University, 280 Daehak-Ro, Gyeongsan, Gyeongbuk 38541, Republic of Korea \\ Correspondence should be addressed to Jae S. Ahn; jsahn@ynu.ac.kr
}

Received 17 January 2018; Revised 22 May 2018; Accepted 24 June 2018; Published 26 July 2018

Academic Editor: Pier Paolo Rossi

Copyright ( $\odot 2018$ Kwang S. Woo et al. This is an open access article distributed under the Creative Commons Attribution License, which permits unrestricted use, distribution, and reproduction in any medium, provided the original work is properly cited.

Based on the assumption that guardrail systems are placed in soil with horizontal ground, interaction behavior between soil and a post has been presented using some relevant theories such as the theory of subgrade reaction, Winkler's spring theory, and the nonlinear $p-y$ curve method. However, they can be constructed on cut slopes or compacted sloping embankments beside the roadway. Thus, the theory based on the conventional discrete spring models cannot be directly applied to the sloping ground since the ground inclination significantly affects the ultimate soil resistance. In this study, two approaches for comparison of them are adopted to present the interaction behavior between soil and the post. One of them is the three-dimensional Lagrangian approach, and the other is the hybrid approach that combines the finite elements and the particles based on SPH (smoothed particle hydrodynamics) modeling. The SPH method is expected to overcome drawbacks of large mesh distortion in soil regions consisting of node-connected finite elements due to lateral movement of the guardrail post. The soil-post interaction in the sloping ground under conditions of quasi-static and dynamic loads is investigated according to ground inclination, embedment length, and embedment location of the post near the slope.

\section{Introduction}

Guardrail systems, consisting of three parts, namely, a guardrail beam, distance spacer, and guardrail post, are constructed along a roadway to prevent vehicles from not only entering into hazardous areas, but also veering onto the other lane of the roadway. These systems, especially the deformable posts, are exposed to considerable lateral loads due to vehicle collisions. To ensure safety of the vehicle's occupants on impact, static and dynamic behavior of a single post in soil has been investigated by numerical methods $[1,2]$ and by full-scale field tests. Nonlinear load-deflection analytical techniques using the theory of subgrade reaction have been considered the most useful analysis of laterally loaded posts embedded in the horizontal ground [3-6]. For instance, Borovinsek et al. [7] performed a computer simulation of impact of trucks on steel road safety barriers in the horizontal ground. $\mathrm{Wu}$ and Thomson [8] studied the interaction between a guardrail post and soil under quasi-static and dynamic loadings. A geometric shape of a soil model was a cylinder in which a single sigma post was anchored in the gravel. The 3D (three-dimensional) finite element modeling and validation for posts of steel guardrails in a roadside with the horizontal ground were studied by Sheikh et al. [9]. This study was conducted to develop conventional finite element models for guardrail posts with $\mathrm{W}$-beam (wide flange beam) subjected to pendulum impact as it deflects in the soil at various embedment lengths. The geometry of the soil model was a hexahedron with $\mathrm{W}$-shaped steel post. However, the well-known Winkler's elastic spring model and nonlinear $p-y$ curve approach for the horizontal ground cannot be directly applied to the sloping ground since the ground inclination significantly affects ultimate resistance of the soil close to guardrail posts.

The 3D finite element modeling is one of the realistic alternatives to predict load-deflection behavior of guardrail posts in the sloping ground subjected to lateral loading. This approach may provide a more precise tool for modeling continuity of soil, interface behavior between soil and a post, and 3D boundary conditions. Lee et al. [6] carried out 
TABLE 1: Modified material parameters in the FHWA soil model.

\begin{tabular}{lcc}
\hline Variables & Description & Values \\
\hline RO & Mass density of soil & $2.35 \times 10^{-6} \mathrm{~kg} / \mathrm{mm}^{3}$ \\
NPLOT & Plotting option & 3 \\
SPGRAV & Specific gravity of soil & 2.79 \\
RHOWAT & Density of water & $1.0 \times 10^{-6} \mathrm{~kg} / \mathrm{mm}^{3}$ \\
VN & Viscoplastic parameter & 1.1 \\
$K$ & Soil's bulk modulus & $11.766 \mathrm{MPa}$ \\
$G$ & Soil's shear modulus & $7.06 \mathrm{MPa}$ \\
PHIRES & Minimum internal friction angle & $0.9 \mathrm{radian}$ \\
INTRMX & Maximum number of plasticity iterations \\
MCONT & Moisture content of soil & 10 \\
ECCN & Eccentricity parameter for third invariant effects & 0.034 \\
COH & Cohesion or shear strength at zero confinement & 0.7 \\
\hline
\end{tabular}

vehicle impact analyses of flexible barriers supported by different shaped posts in the sloping ground. Nevertheless, it is still argued that conventional Lagrangian finite element methods may result in an artificially high resistance due to excessive mesh distortion in the soil region as the movement of posts occurs considerably [9]. This is because most of these works are based on the node-connected Lagrangian finite element methods. Thus, a suitable approach is needed to separate the soil from the post. It is expected that SPH (smoothed particle hydrodynamics) methods based on meshless approaches would reduce any excessive soil stiffness resulting from deterioration of mesh quality in the soil region. Generally, the SPH methods appear to be powerful and useful for those problems that involve large displacements [9-11] due to impact, explosion, and penetration.

In this study, lateral resistance of guardrail posts near a slope is investigated under quasi-static and dynamic loadings with respect to several parameters including embedment length, ground inclination, and embedment location of posts. Two computational models are used, namely, the conventional 3D finite element method and the hybrid SPH method afforded by LS-DYNA [12]. The FHWA (Federal Highways Administration) soil model [13] is adopted for application to road-base soils.

\section{FHWA Soil Model in LS-DYNA}

Soils are primarily classified in terms of their particle-size distribution depending on the relative proportions of clay, silt, and sand within the solid phase. To obtain reliable analysis results, it is necessary that suitable material models of the soils are considered. To evaluate the soil material model, it is important that the actual physical tests of soils are implemented. However, because this study is concerned with numerical analysis approaches, the FHWA soil models developed by Lewis [13] and Kulak and Schwer [14] are just adopted for application to road-base soils, which are determined by two triaxial compression tests and a hydrostatic tension test. For analysis of LS-DYNA to predict the dynamic performance of roadside safety structures embedded in the horizontal or sloping ground subjected to a vehicle impact, twelve main input parameters reflecting the FHWA soil model are shown in Table 1 . They are density in an initial state of soils, bulk and shear modulus, compaction curve, yield surface, and so on. Some input data of the original material parameters given by the FHWA soil model have been slightly modified in Table 1. An elastic modulus of soil is assumed to be $18 \mathrm{MPa}$ referring to the results from Yoshida's SPT (standard penetration test) [15]. Thus, stiffness parameters $K$ and $G$ are modified considering the elastic modulus. Minimum internal friction angle (PHIRES) is related to residual shear strength. It is known from direct shear tests of Lewis [13] that there is a gradual decrease in shear strength after a peak. For a value of PHIRES, the residual shear strength is assumed to be $80 \%$ of the peak value. Also, a viscoplastic parameter is considered to represent the strain rate effects. It can account for effect of a confinement pressure on a yield stress in a modified Mohr-Coulomb failure surface. This FHWA soil model is applied to Lagrangian solid elements and SPH nodes. The more detailed description of the input parameters in Table 1 has been presented in [6].

\section{Smoothed Particle Hydrodynamics Method}

A SPH method is one of meshless Lagrangian methods developed initially to simulate astrophysical problems $[16,17]$. This method is based on a particle approximation and has two basic steps. The first step is to discretize any domain using a set of arbitrarily distributed particles where no connectivity is needed. The kernel approximation of a function $f(\mathbf{x})$ can be defined as follows:

$$
f(\mathbf{x})=\int_{\Omega} f\left(\mathbf{x}^{\prime}\right) \delta\left(\mathbf{x}-\mathbf{x}^{\prime}\right) d \mathbf{x}^{\prime},
$$

where $f$ is a function of the position vector $\mathbf{x}$ and $\delta\left(\mathbf{x}-\mathbf{x}^{\prime}\right)$ is the Dirac delta function. Also, $\Omega$ is the volume of the integral that contains $\mathbf{x}$. Since the Dirac delta function is exact and rigorous as long as $f(\mathbf{x})$ is defined and continuous in $\Omega$, (1) cannot be used for establishing discrete numerical models. If the Dirac delta function is replaced by a suitable smoothing function of $W\left(\mathbf{x}-\mathbf{x}^{\prime}, h\right)$ with a finite spatial dimension $h$, the kernel approximation of $f(\mathbf{x}),\langle f(\mathbf{x})\rangle$, becomes

$$
\langle f(\mathbf{x})\rangle \cong \int_{\Omega} f\left(\mathbf{x}^{\prime}\right) W\left(\mathbf{x}-\mathbf{x}^{\prime}, h\right) d \mathbf{x}^{\prime}
$$

where $h$ is the smoothing length defining the influence or support area of the smoothing function $W$. The kernel 


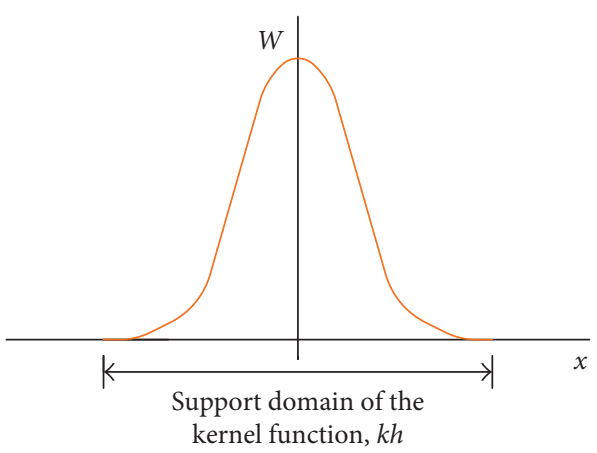

Figure 1: Typical form of kernel function.

approximation interpolates the position of the particles within the domain that should satisfy several requirements, namely, an even function, compact condition, normalization condition, and delta function property, which means the smoothing function should satisfy the Dirac delta function condition as the smoothing length $h$ approaches zero as shown in Figure 1. The field functions approximated by the integral representation based on the Dirac delta function are used for the kernel approximation. Thus, the kernel approximation describes the smoothing effect in the weak form [18].

The second step is numerical discretization at each time step using a process that may be classified into the kernel approximation and particle approximation. The particle approximation in (3) and (4) converts the continuous integral representation based on the kernel approximation of a displacement function and its derivatives into discretized forms of summation over all of the particles in a local domain, the so-called support domain. They are characterized by the smoothing length $h$ and a scalar constant $k$ which means the domain where the information for all of the points inside this domain is used to determine the information at a certain point $\mathbf{x}$ :

$$
\begin{aligned}
\langle f(\mathbf{x})\rangle & \cong \sum_{j=1}^{N} f\left(X_{j}\right) W\left(X-X_{j}, h\right) \Delta V_{j} \\
& =\sum_{j=1}^{N} f\left(X_{j}\right) W\left(X-X_{j}, h\right) \frac{1}{\rho_{j}}\left(m_{j}\right), \\
\left\langle f\left(X_{i}\right)\right\rangle & =\sum_{j=1}^{N} \frac{m_{j}}{\rho_{j}} f\left(X_{j}\right) W\left(X-X_{j}, h\right) .
\end{aligned}
$$

Considering the problem domain $\Omega$ filled with a set of particles in Figure 2, these particles can be used only for integration and interpolation to represent material properties. One particle $i$ is associated with a fixed lumped volume $\Delta V_{i}$ in (3). If the particle mass and density are known, the lumped volume can also be replaced by the corresponding mass-to-density ratio denoted by $m_{i} / \rho_{i}$, in (4), where $N$ represents the total number of the particles within the support domain.

Substituting $f(\mathbf{x})$ with $\nabla \cdot f(\mathbf{x})$ in (2) and integrating by parts, we obtain the derivative of the function by using the divergence theorem in (5) and (6). Thus, the gradient is

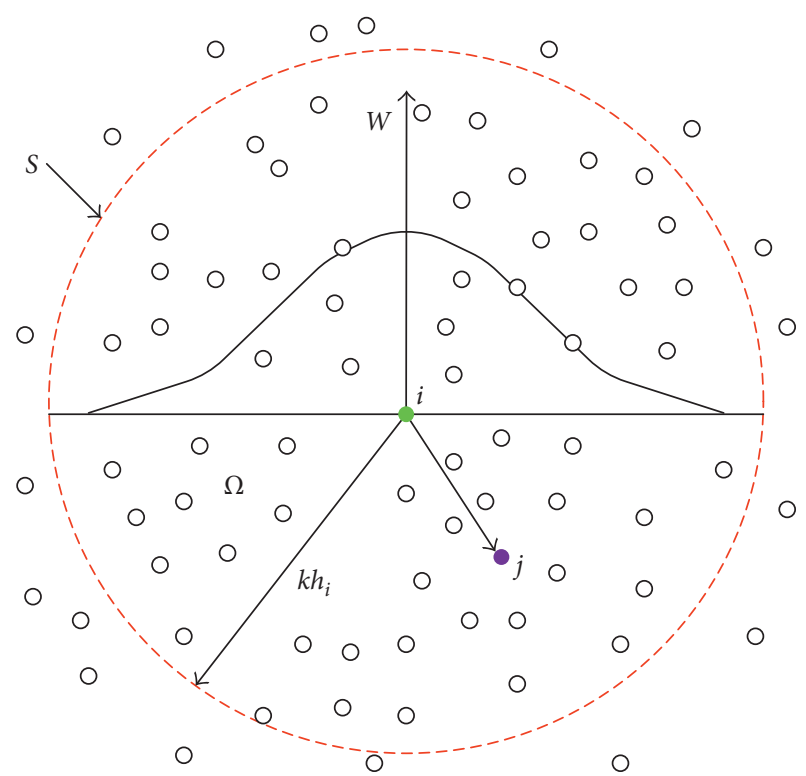

FIGURE 2: SPH concept in the problem domain $\Omega$ with the surface $S[15]$.

determined from the values of $f$ and the derivatives of $W$, rather than from the derivatives of the function itself. However, the SPH method does not guarantee the convergence of the solution, since this approach does not satisfy the consistency conditions, including rigid body motion, the constant strain state, and the compatibility condition:

$$
\begin{aligned}
& \langle\nabla \cdot f(\mathbf{x})\rangle=\int_{\Omega}\left[\nabla f\left(\mathbf{x}^{\prime}\right)\right] W\left(\mathbf{x}-\mathbf{x}^{\prime}, h\right) d \mathbf{x}^{\prime}, \\
& \langle\nabla \cdot f(\mathbf{x})\rangle=-\int_{\Omega} f\left(\mathbf{x}^{\prime}\right) \nabla W\left(\mathbf{x}-\mathbf{x}^{\prime}, h\right) d \mathbf{x}^{\prime} .
\end{aligned}
$$

\section{Numerical Examples}

4.1. Soil-Post Interaction under Quasi-Static Loading. In this example, two approaches are considered to model the soil region. They are a conventional 3D finite element method and a hybrid method that combines Lagrangian finite elements and particles based on the SPH technique. Figure 3 shows a laterally loaded guardrail post embedded in the sloping ground $\left(\theta=30^{\circ}\right)$. In Figure 3(a), the soil region is modeled by only the 3D Lagrangian FE (finite elements) method, which adopts a regular refined mesh with $1 \mathrm{~mm}$ of the most elements' size. In Figure 3(b), the soil region near the guardrail post is modeled by SPH particles in which large deformation of soils occurred. The soil region with the SPH particles has width $4 D$ and depth $12 D$, and the other region of the soils consists of conventional 3D finite elements. In Figure 3, $D$ refers to the width of the guardrail post. The steel post with a square tube section is modeled by the four-node Belytschko-Tsay shell elements with three integration points and piecewise linear plasticity model (MAT24) available in LS-DYNA. In the cross section of the steel post, the width $D$ is $125 \mathrm{~mm}$ and the thickness is $4 \mathrm{~mm}$. Table 2 shows the input parameters of the steel materials. The material model of the 


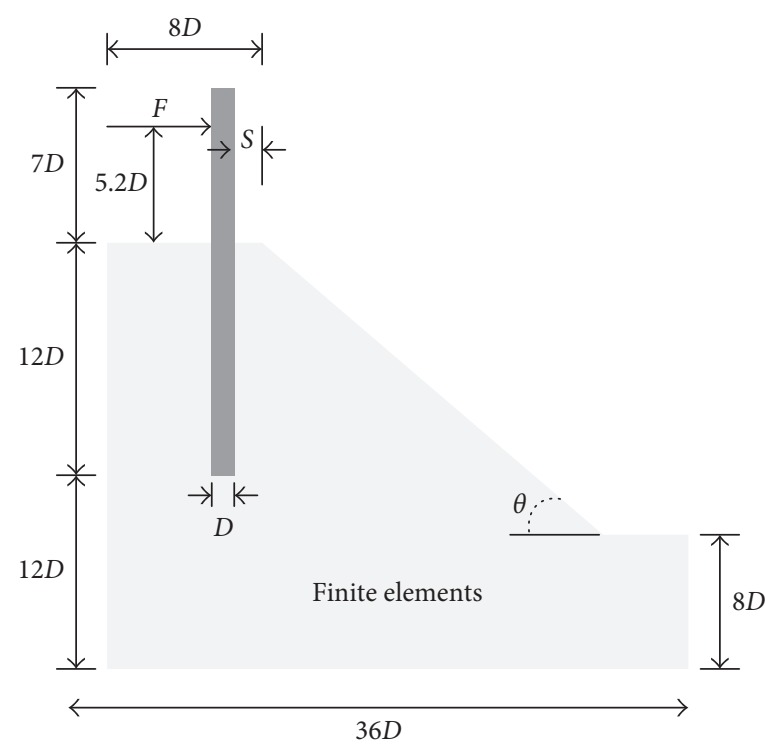

(a)

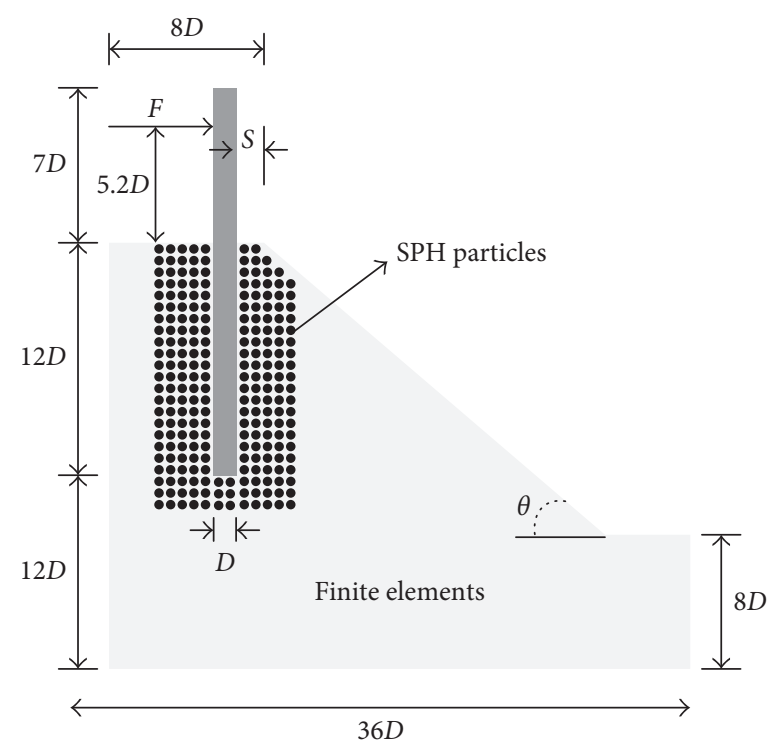

(b)

FIgURE 3: Geometric configuration of two different models for the sloping ground. (a) Finite element model. (b) Hybrid SPH model.

TABLE 2: Input data of the piecewise linear plasticity model for the steel post.

\begin{tabular}{lccc}
\hline Density $\left(\mathrm{t} / \mathrm{mm}^{3}\right)$ & Elastic modulus $(\mathrm{MPa})$ & Poisson's ratio & Yield stress $(\mathrm{MPa})$ \\
\hline $7.85 \times 10^{-9}$ & $2.1 \times 10^{5}$ & 0.3 & 250 \\
\hline
\end{tabular}
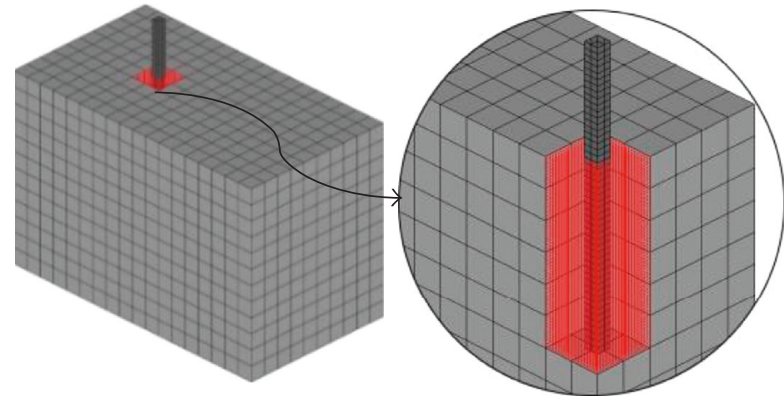

Figure 4: Hybrid SPH model of a single guardrail post in the horizontal ground for $\mathrm{SPH}$ pitch $=25 \mathrm{~mm}$.

soil is based on FHWA soil (MAT147) in LS-DYNA presented in Table 1 . The soil model was developed by the USA Federal Highway Administration for applications of roadbase soils.

The boundary conditions in the bottom surfaces of the soil are fixed in all directions and in the vertical surfaces; the boundary conditions are fixed with respect to only the normal direction. There is no boundary condition in the top and inclined surfaces. Also, a lateral load $F$ is applied to the post at a height of $5.2 D(650 \mathrm{~mm})$ above the ground. The contact between the soil and the single steel guardrail post is modeled with the contact_automatic_surface_to_surface option where the friction coefficient at interfaces is fixed as 0.5. Also, the contact_tied_node_to_surface command is applied to the interfaces between the SPH particle and the Lagrangian element to avoid the SPH particles penetrating the Lagrangian elements. Figures 4 and 5 show the modeling configuration of

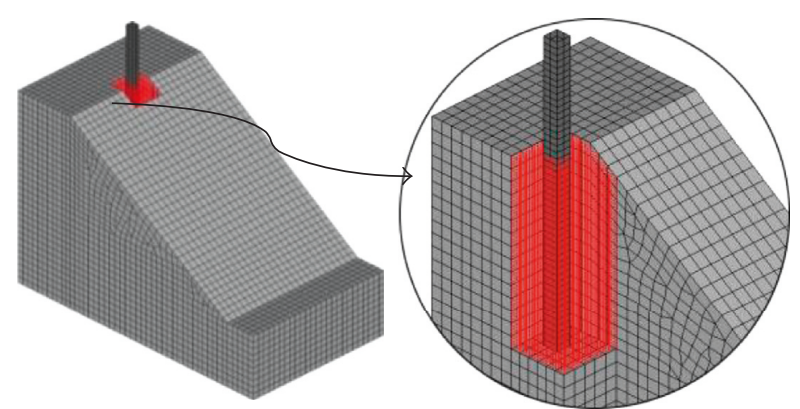

FIgURE 5: Hybrid SPH model of a single guardrail post in the sloping ground for $\mathrm{SPH}$ pitch $=25 \mathrm{~mm}$.

the hybrid SPH method in the cases of the horizontal and sloping grounds, respectively. In this study, the pitches (or particle spacing) for the hybrid SPH model are considered to be $12.5,25$, and $50 \mathrm{~mm}$ to check the convergence of the solutions. Figure 6 shows that the convergence characteristics of the displacement pattern detected as the pitches are reduced from 50 to $12.5 \mathrm{~mm}$. From the results of the convergence tests, the pitch is fixed at $25 \mathrm{~mm}$. The required element numbers of the hybrid SPH method and the 3D FE method are 26,901 and 2136 for the horizontal ground, respectively. Also, their numbers are 25,620 and 24,800 for sloping ground, respectively, as shown in Table 3. Meanwhile, for the $3 \mathrm{D} \mathrm{FE}$ method, convergence tests were implemented from coarse to fine meshes. Based on the results of the convergence tests, soil regions are composed of the elements with approximate $100 \mathrm{~mm}$ of the length as regular as possible. 


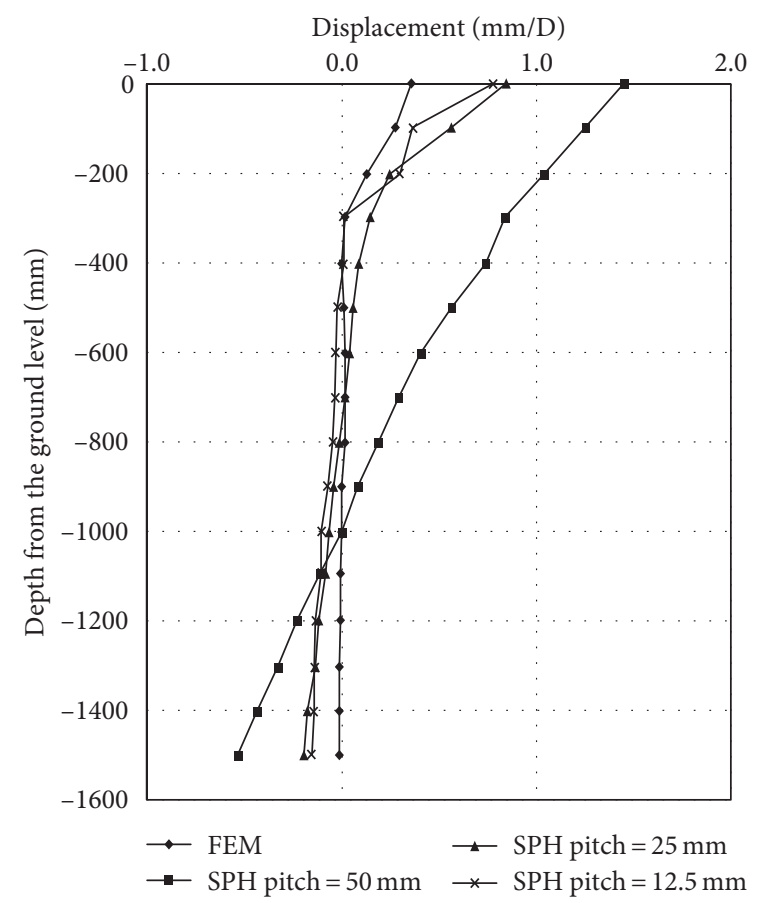

FIGURE 6: Convergence of lateral displacements with respect to the SPH pitch.

TABLE 3: Numbers of elements by proposed models according to different SPH particle spacing.

\begin{tabular}{lcccc}
\hline \multirow{2}{*}{ SPH pitch $(\mathrm{mm})$} & \multicolumn{2}{c}{ SPH region } & \multicolumn{2}{c}{ FE region } \\
& Horizontal & Sloping & Horizontal & Sloping \\
\hline 50 & 3751 & 3498 & & \\
25 & 26,901 & 25,620 & 2136 & 24800 \\
12.5 & 203,401 & 195,693 & & \\
\hline
\end{tabular}

The lateral displacements of the guardrail post at the loading point are computed for horizontal and sloping grounds, respectively. In the case of horizontal ground, the ultimate lateral loads of the steel post are found to be $45.4 \mathrm{kN}$ by the hybrid SPH analysis and $51.7 \mathrm{kN}$ by the $3 \mathrm{D} \mathrm{FE}$ analysis from Figure 7. In addition, the ultimate lateral loads for the sloping ground are computed to be $41.0 \mathrm{kN}$ by the hybrid SPH method and $45.3 \mathrm{kN}$ by the conventional finite element method.

Meanwhile, to show validation of the numerical techniques considering quasi-static loading, the results of a physical experiment are compared to numerical results. Figures $8(\mathrm{a})$ and $8(\mathrm{~b})$ show the experimental field in which the quasi-static loading tests were implemented. In addition, Figure 9 represents a simplified loading system to find loading-displacement relation at the posts of guardrails. In the tests, lateral loads were applied to the post at a height of $5.2 \mathrm{D}(650 \mathrm{~mm})$ above the ground. A rigid cover plate with a thickness of $4 \mathrm{~mm}$ is wrapped around a post at the loading point and pulled at a displacement rate of $100 \mathrm{~mm} / \mathrm{sec}$. The experimental configuration is similar to that of the numerical methods. In the in situ experiment, mechanical dial gauges were used to measure the horizontal displacements of

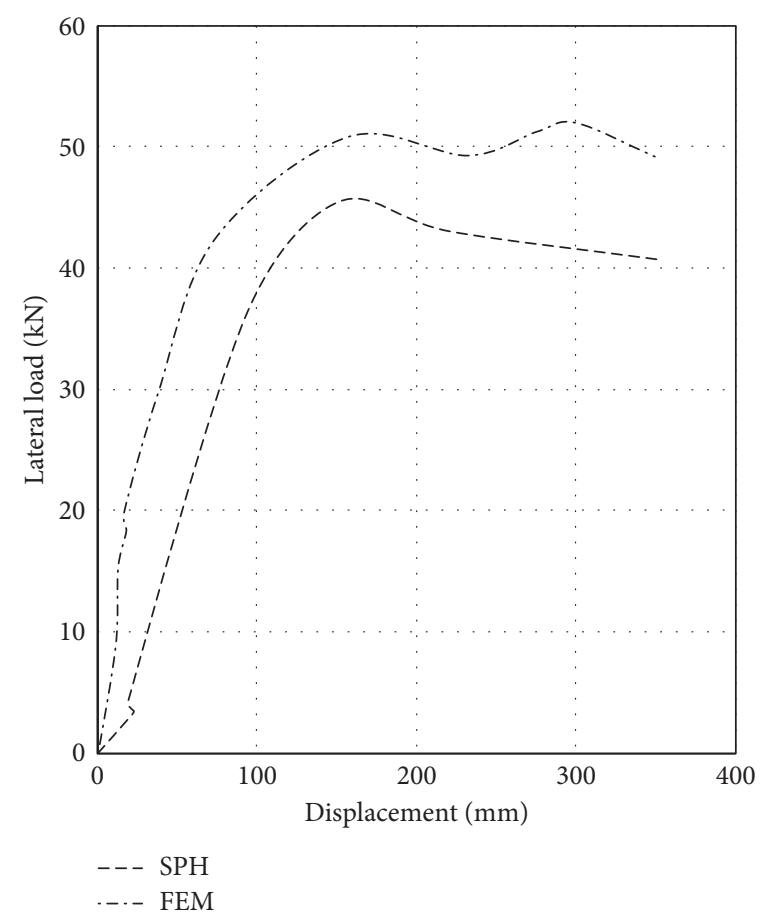

FIgURE 7: Load-displacement relation for the horizontal case.

the pile head. The lateral displacements of the steel post were measured as functions of the applied forces, and the measured lateral loads could be obtained from contact forces between the rigid cover plate and the post. These tests were conducted at KECRI (Korea Expressway Corporation Research Institute), which is the main test facility for testing road equipment in Korea. Due to the experimental cost, only static test results for the sloping ground could be obtained. Each test is terminated when the loading point exceeds a lateral displacement of $400 \mathrm{~mm}$. In the sloping ground, the test pile is placed in the top edge of the slope and same location is adopted for horizontal ground. Figure 10 shows comparison of the numerical and experimental results. The ultimate load from the SPH method with $41.0 \mathrm{kN}$ is closer to that of the experiment with $40.0 \mathrm{kN}$ than that of the conventional finite element with $45.3 \mathrm{kN}$. Although the initial load-displacement curve of the SPH method has a little bit difference with those of the FEM and the experiment, smaller pitch sizes of the SPH method make it closer to those without considerable variation of ultimate loading values. Therefore, it is noted from the results that the result of the hybrid SPH model agrees better with the experimental result than that of the conventional finite element model. This may be attributed to the large distortion effect of the soil meshes when the conventional 3D Lagrangian finite element approach is adopted. Unfortunately, because any experimental test was not carried out for the horizontal ground, there are no experimental data in Figure 7. Also, it is shown from Figures 7 and 10 that the ultimate lateral load of the steel post is decreased by approximately $11-14 \%$ due to the effect of the ground inclination. Flexural failure of guardrail posts would be more significant than the failure of soils, since the horizontal load above the ground induces a bending moment 


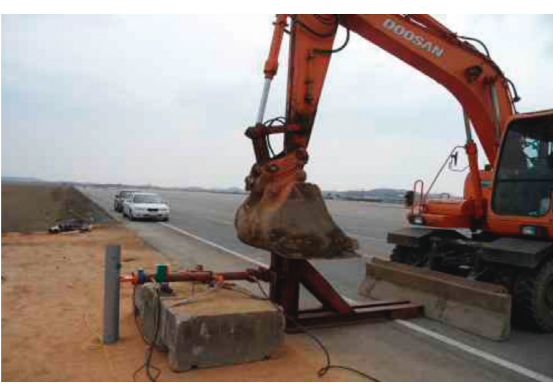

(a)

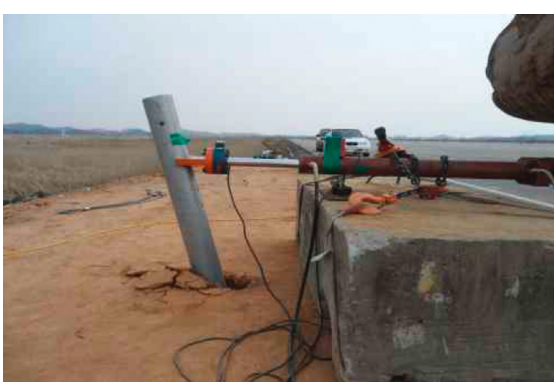

(b)

Figure 8: Loading-displacement test of the guardrail post. (a) Installation of a guardrail post. (b) Deformation of a guardrail post.

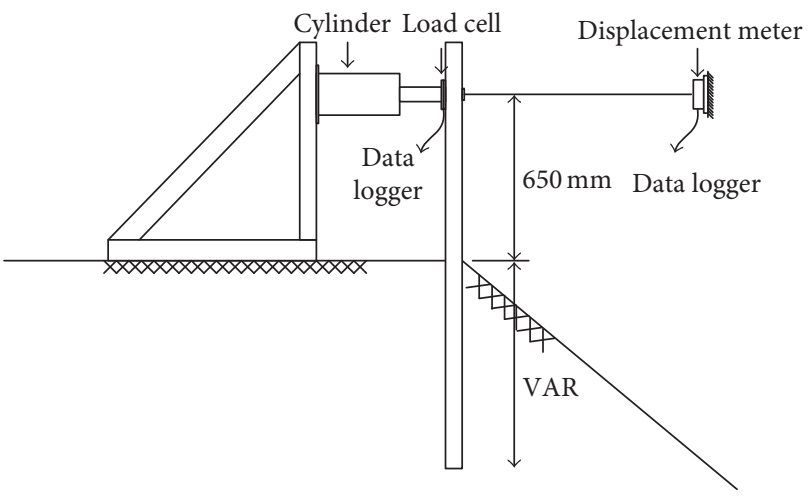

FIGURE 9: Typical test setup of the experiment for the sloping ground.

about the ground surface. Variations of lateral displacements and von Mises stresses are graphically shown in Figures 11 and 12 as the lateral loads are increased from 20 to $40 \mathrm{kN}$. As expected, the zone of maximum displacements spread out and their magnitudes rise drastically with increase of the lateral loads, while for maximum stress region of soils is very small regardless of increase of the lateral loads and variation of their values is less than that of displacements of the posts. However, these tendencies would be changed according to the elastic modulus that is dependent upon type of soils.

Meanwhile, the influence of the embedment location of the guardrail posts is examined by the hybrid SPH method proposed in this study. The edge distances $S$ shown in Figure 3 are varied from 0 to $3 D$ when the embedment length is fixed as $1500 \mathrm{~mm}$ where $D$ represents the side length of the steel posts. Figure 13 shows that the effect of the ground inclination would be negligible, when the edge distances are not smaller than $2 D$. Also, the influence on variation of the embedment lengths of the steel posts in the range from 1100 to $1500 \mathrm{~mm}$ is investigated when the edge distance $S$ is fixed as zero. It is observed from Figure 14 that the increase of the lateral resistance of the posts is marginal when the embedment length exceeds $1100 \mathrm{~mm}$. However, the results may additionally be dependent on different shapes of the posts such as W-shape, C-shape, and circular shape, since the passive resistance between the soil and the post may be dependent upon the shape of the posts.

4.2. Soil-Post Interaction under Dynamic Loading. The same numerical models used in the previous quasi-static analyses

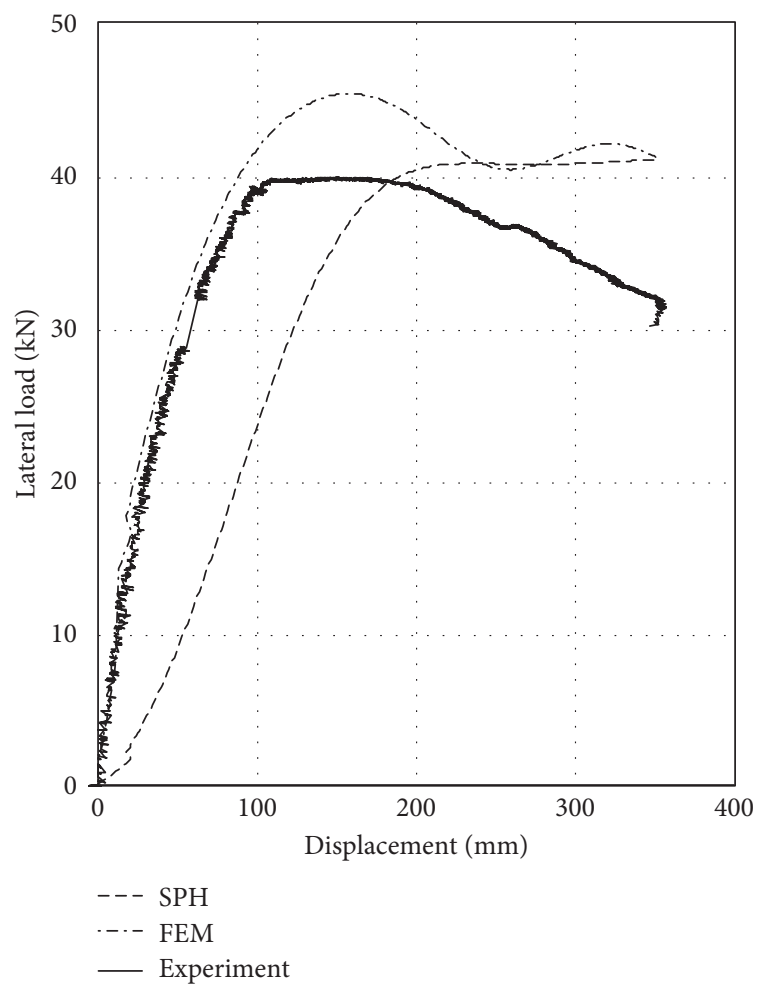

Figure 10: Load-displacement relation for the sloping case.

have been tested with $840 \mathrm{~kg}$ pendulum released from the horizontal position at a fixed height $(h)$ of $2.8 \mathrm{~m}$. The theoretical impact velocity $v$ calculated by $v=\sqrt{2 g h}$ is $7.4 \mathrm{~m} / \mathrm{sec}$, where $g$ is the acceleration due to gravity. The lateral displacements are measured at an impact point of the steel posts that are $650 \mathrm{~mm}$ away from the ground. The impact force can be calculated by the mass and acceleration of the pendulum during impact. The configurations using a hybrid SPH method are illustrated in Figure 15 to simulate the pendulum tests for the horizontal and sloping cases, respectively.

From the results of the conventional finite element method, Figures 16 and 17 show deformed states and von Mises stresses of the posts calculated under the dynamic loading like impact of the pendulum for the horizontal and sloping grounds. As shown in these figures, the plastic zone of the posts is in the vicinity of the ground surface due to the bending moments, and it is observed that the von Mises 

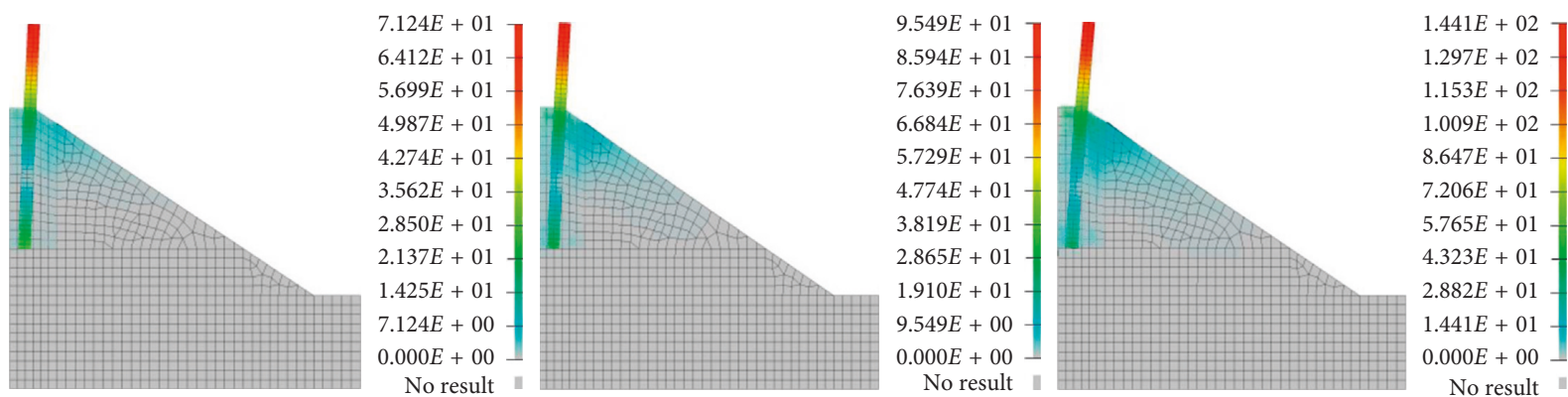

Figure 11: Displacement pattern of the post with respect to load increment by the hybrid SPH model. (a) $F=20 \mathrm{kN}$. (b) $F=30 \mathrm{kN}$. (c) $F=40 \mathrm{kN}$.
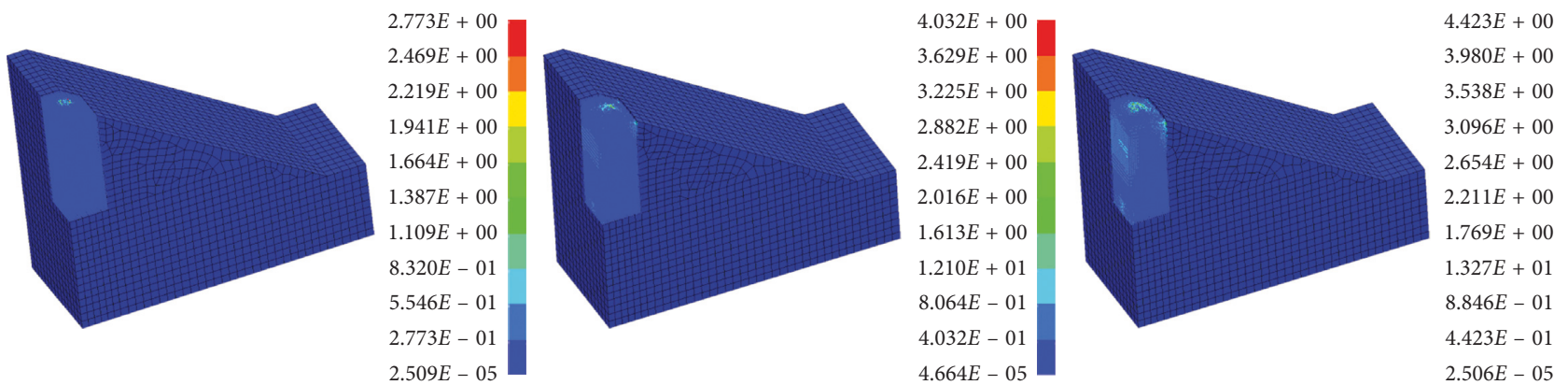

Figure 12: von Mises stress pattern of soil with respect to load increment by the hybrid SPH model. (a) $F=20 \mathrm{kN}$. (b) $F=30 \mathrm{kN}$. (c) $F=40 \mathrm{kN}$.

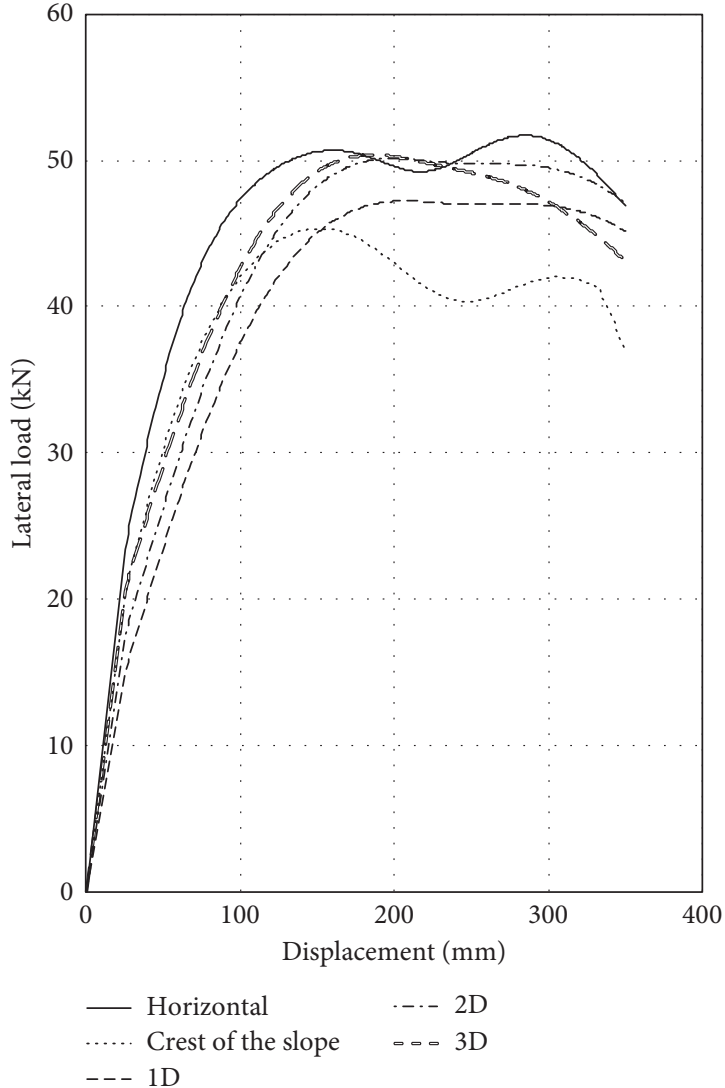

FIGURE 13: Influence of edge distance from the crest for the sloping case.

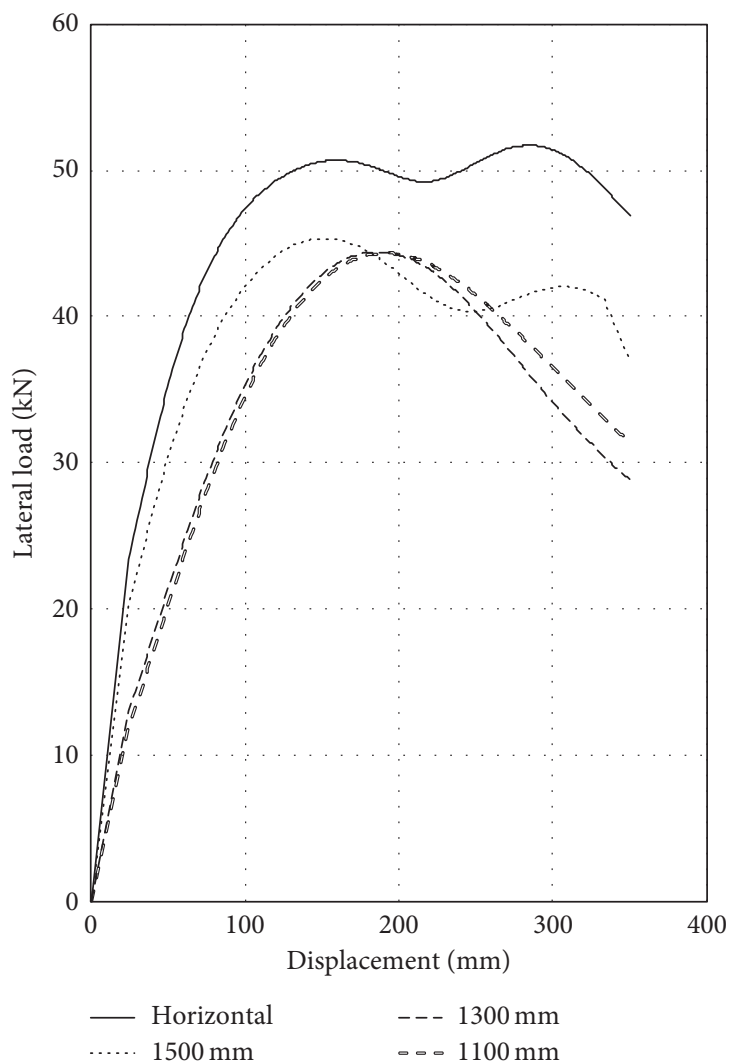

FIGURE 14: Influence of embedment length of the steel post for the sloping case. 


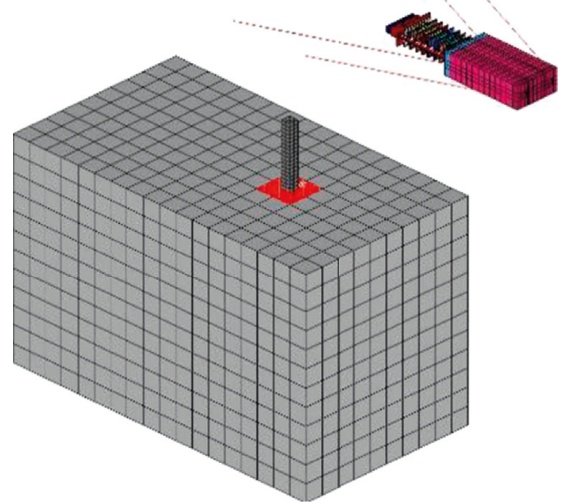

(a)

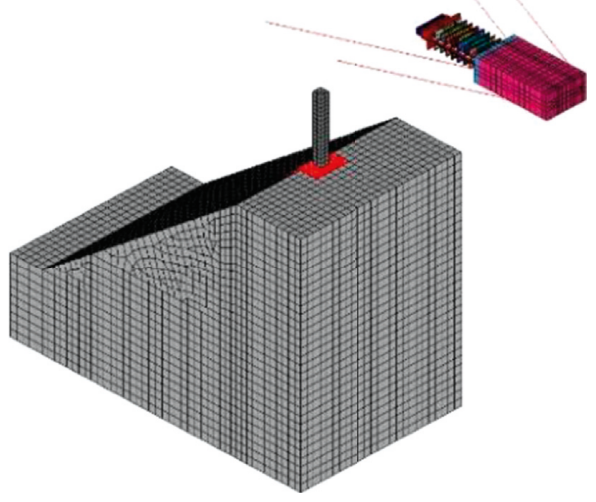

(b)

Figure 15: Hybrid SPH model for the pendulum test. (a) Horizontal case. (b) Sloping case.

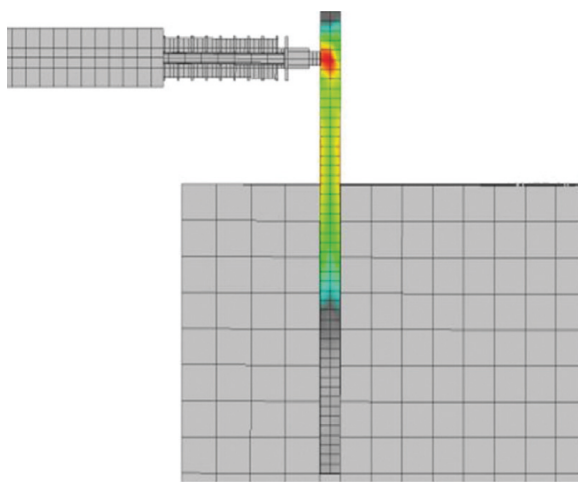

(a)

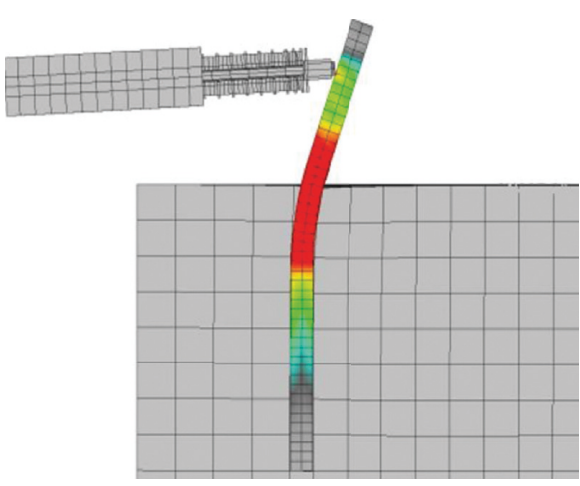

(c)

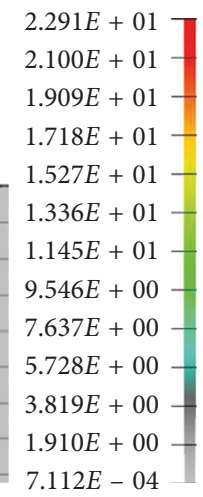

$2.500 E+02$
$2.292 E+02-7$
$2.083 E+02-$
$1.875 E+02-$
$1.667 E+02-$
$1.458 E+02-$
$1.250 E+02-$
$1.042 E+02-$
$8.333 E+01-$
$6.250 E+01$
$4.167 E+01-$
$2.083 E+01-$
$6.195 E-04$

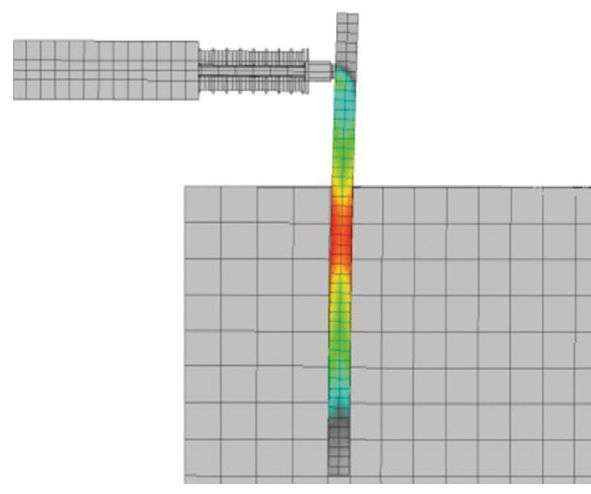

(b)

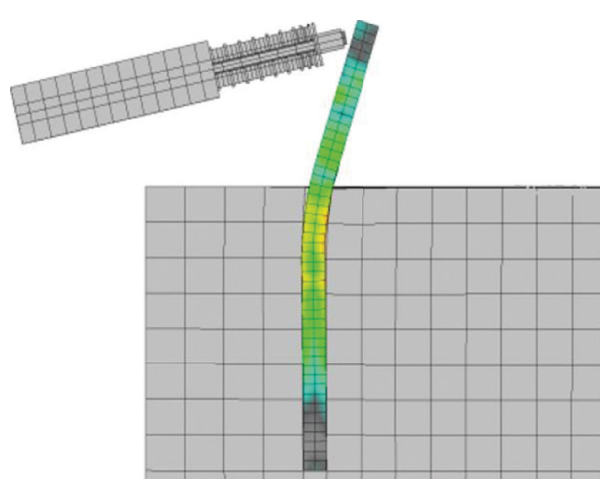

(d)
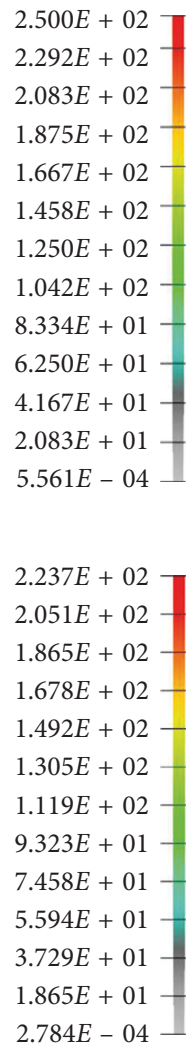

$5.561 E-04$

$2.784 E-0$

Figure 16: von Mises stress and displacement of steel posts for the horizontal cases.

stress corresponding to the maximum lateral displacements are slightly reduced due to the elastic recovery of the pendulum after it rebounds from the steel post. The ultimate lateral load of $49.1 \mathrm{kN}$ for the sloping ground is found to be $15 \%$ less than the value of $56.5 \mathrm{kN}$ for the horizontal ground. In the case of using the hybrid SPH method, the similar patterns shown in Figures 16 and 17 are also obtained except existence of the SPH particles. Figures 18 and 19 show load and displacement curves for the horizontal and sloping grounds, respectively. From the figures, the ultimate lateral loads $45.8 \mathrm{kN}$ and $51.1 \mathrm{kN}$ can be obtained. The dynamic loading cases show approximately $11-14 \%$ reduction of the ultimate lateral loads due to the ground inclination effects like the results of the quasi-static loading tests. The displacements and ultimate loads in the dynamic loading afforded by the 3D finite element model are summarized in Table 4, while a comparison of the ultimate lateral loads for the conventional method and the hybrid SPH method is given in Table 5 with 


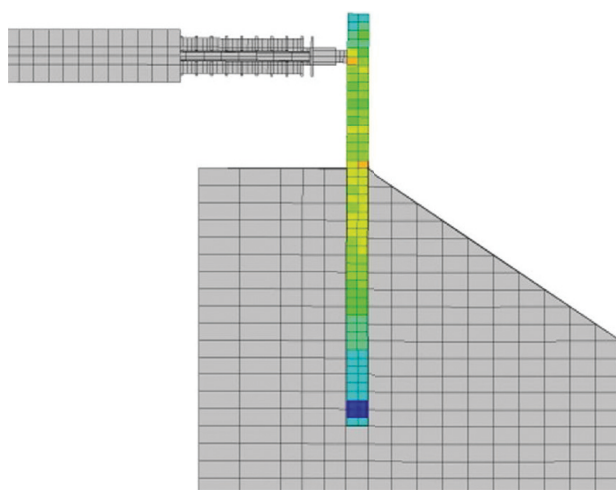

(a)

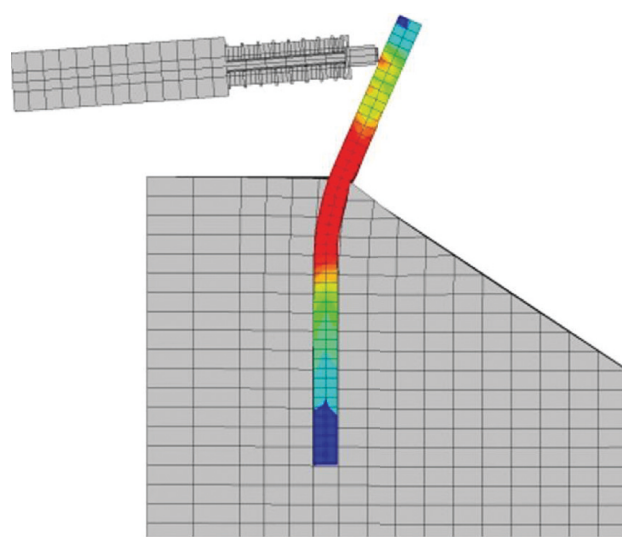

(c)

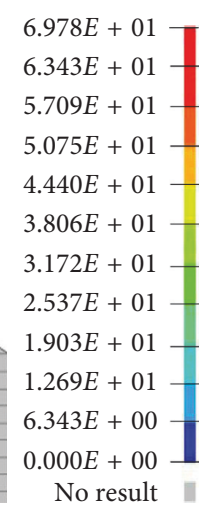

FIGURE 17: von Mises stress and displacement of posts for the sloping cases.

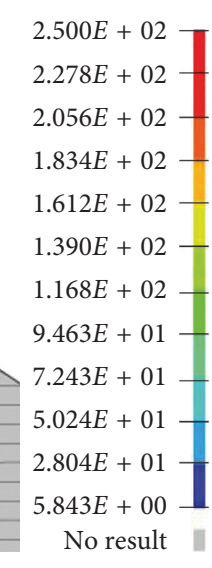

(d)

isplacement of posts for the sloping cases.

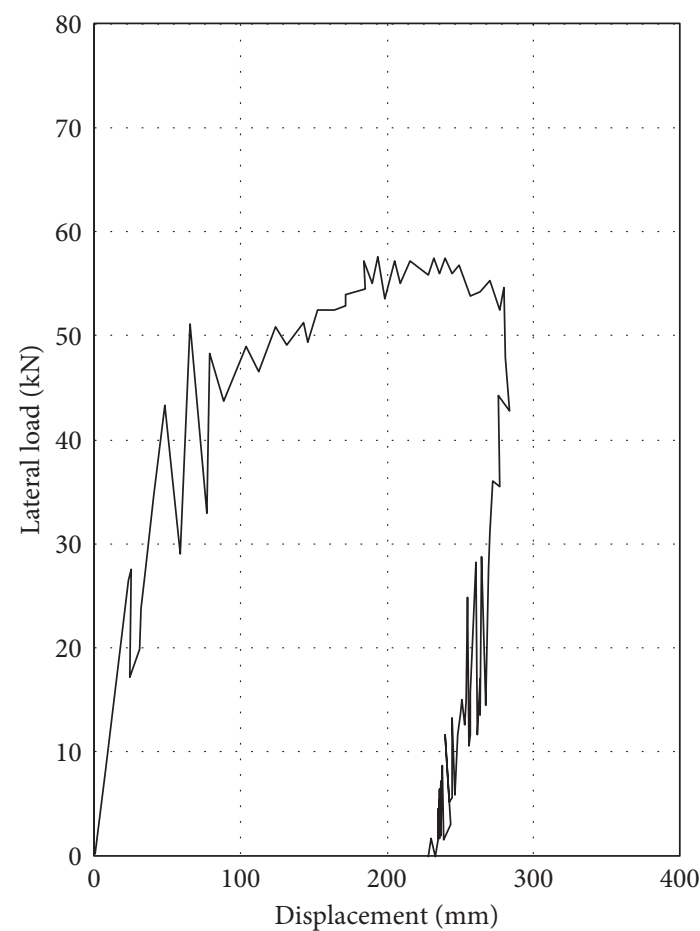

FIGURE 18: Lateral load-displacement relations for a horizontal case.
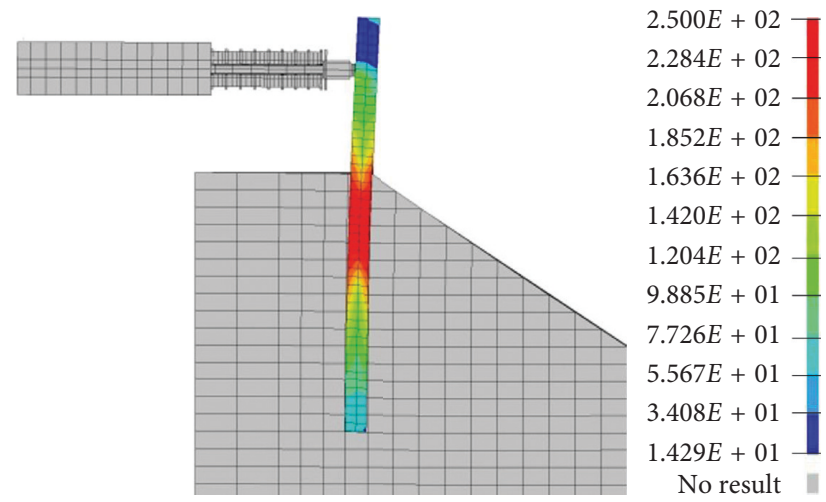

(b)

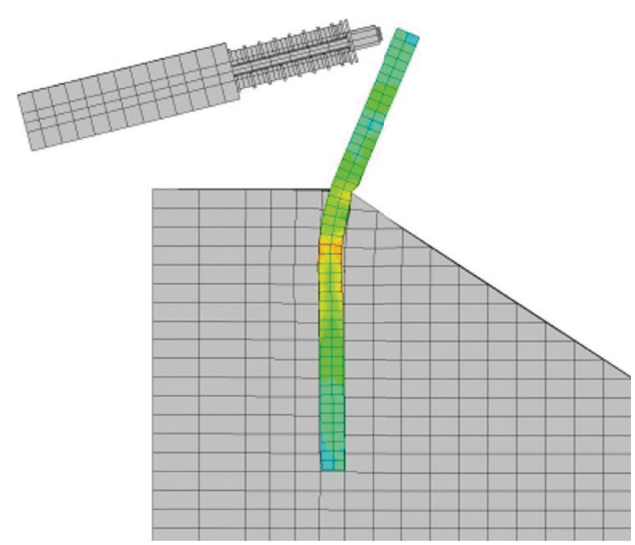

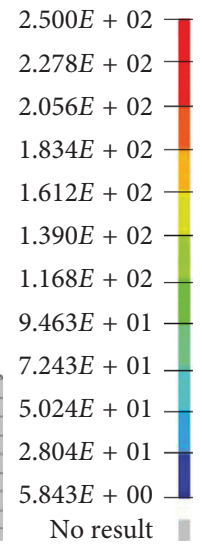

No result 
TABLe 4: Displacements and ultimate loads in dynamic loading.

\begin{tabular}{|c|c|c|c|c|c|}
\hline & Cases & & $\begin{array}{c}\text { Maximum dynamic } \\
\text { deflection }(\mathrm{mm})\end{array}$ & $\begin{array}{c}\text { Permanent } \\
\text { deflection }(\mathrm{mm})\end{array}$ & $\begin{array}{c}\text { Ultimate lateral } \\
\text { load }(\mathrm{kN})\end{array}$ \\
\hline \multirow[t]{4}{*}{ Horizontal ground } & & & 280.2 & 230.8 & 56.5 \\
\hline & \multirow{4}{*}{ Edge distance $S$} & 0 & 347.3 & 308.4 & 49.1 \\
\hline & & $1 D$ & 314.1 & 267.0 & 48.6 \\
\hline & & $2 D$ & 304.5 & 256.1 & 53.4 \\
\hline \multirow[t]{4}{*}{ Sloping ground } & & $3 D$ & 299.7 & 252.7 & 53.8 \\
\hline & \multirow{3}{*}{ Embedment length $L$} & 1100 & 378.5 & 345.7 & 48.1 \\
\hline & & 1300 & 365.1 & 331.0 & 48.5 \\
\hline & & 1500 & 347.3 & 308.4 & 49.1 \\
\hline
\end{tabular}

TABLE 5: Comparison of ultimate lateral loads with the experimental result.

\begin{tabular}{|c|c|c|c|c|c|}
\hline \multirow{2}{*}{ Tests } & & \multicolumn{3}{|c|}{ Ultimate lateral loads $(\mathrm{kN})$} & \multirow{2}{*}{ Reduction rate } \\
\hline & & FEM & SPH & Experiment & \\
\hline Quasi-static loading & $\begin{array}{l}\text { Horizontal } \\
\text { Sloping }\end{array}$ & $\begin{array}{l}51.7 \\
45.3 \\
\end{array}$ & $\begin{array}{l}45.4 \\
41.0 \\
\end{array}$ & $\overline{40.0}$ & $11 \sim 14 \%$ \\
\hline Dynamic loading & $\begin{array}{l}\text { Horizontal } \\
\text { Sloping }\end{array}$ & $\begin{array}{l}56.5 \\
49.1 \\
\end{array}$ & $\begin{array}{l}51.1 \\
45.8 \\
\end{array}$ & - & $12 \sim 15 \%$ \\
\hline
\end{tabular}

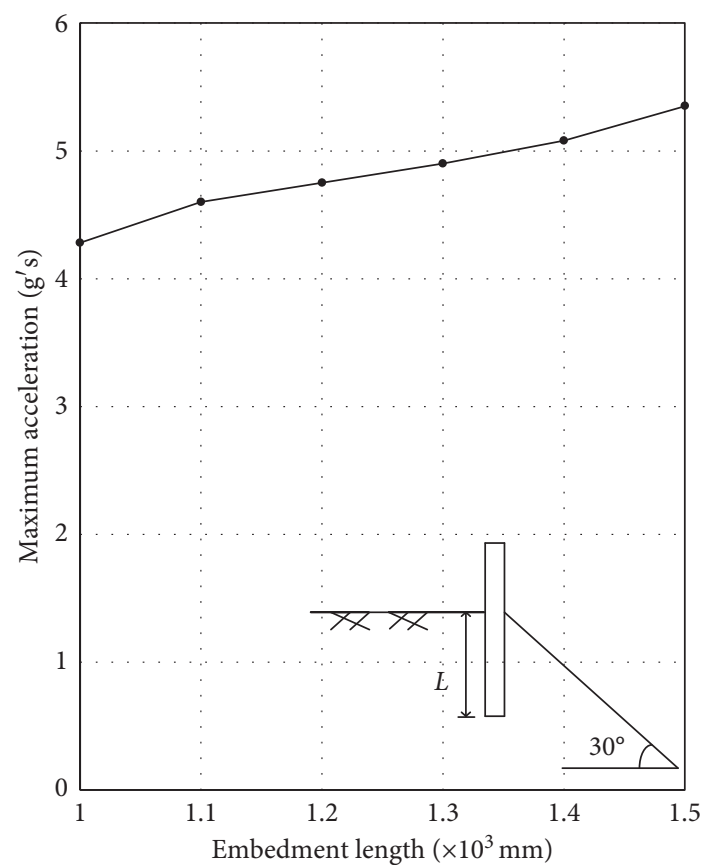

Figure 20: Variation of maximum accelerations of the pendulum according to embedment lengths.

reference to the experimental data for only the sloping ground obtained from the experiments implemented by KECRI. The variations of the maximum accelerations of the pendulum and maximum lateral loads are shown in Figures 20 and 21, respectively, for different embedment lengths of the steel post. Influences on the embedment location and edge distance $S$ are plotted in Figures 22 and 23, respectively. Similar to the case of the quasi-static loading tests, the effects of the embedment length and embedment location would be negligible when the former exceeds $1100 \mathrm{~mm}$ and the latter is greater than $S=2 D$.

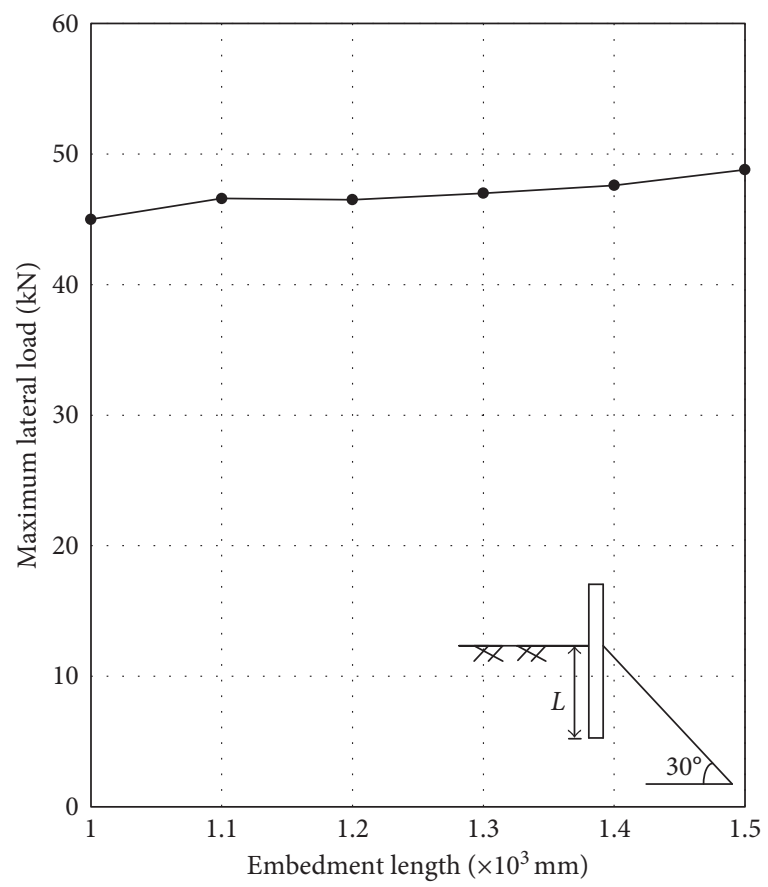

FIgURE 21: Variation of maximum lateral loads according to embedment lengths.

\section{Conclusions}

In the present investigation, the conventional 3D finite element approach and the hybrid approach that combines Lagrange and SPH (smoothed particle hydrodynamics) elements have been tested to evaluate the response of a laterally loaded single guardrail post with square tube embedded in the sloping ground. These approaches seem to be suitable to model the ground slope, as well as to obtain response of the soil-post system dominated by bending deformations. The results of them are compared with the 


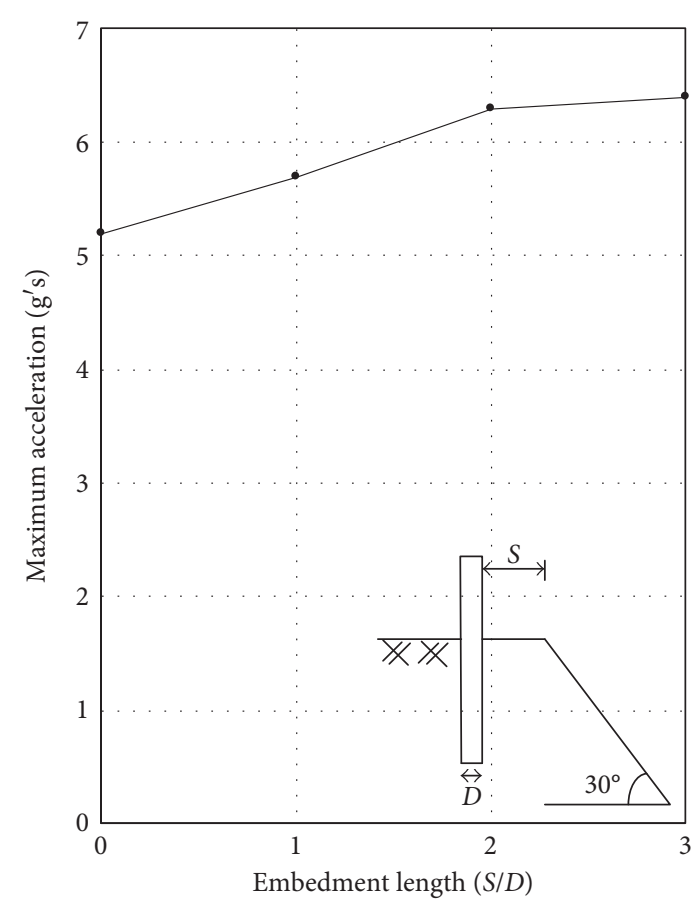

FIGURE 22: Variation of the maximum acceleration of the pendulum according to the embedment location.

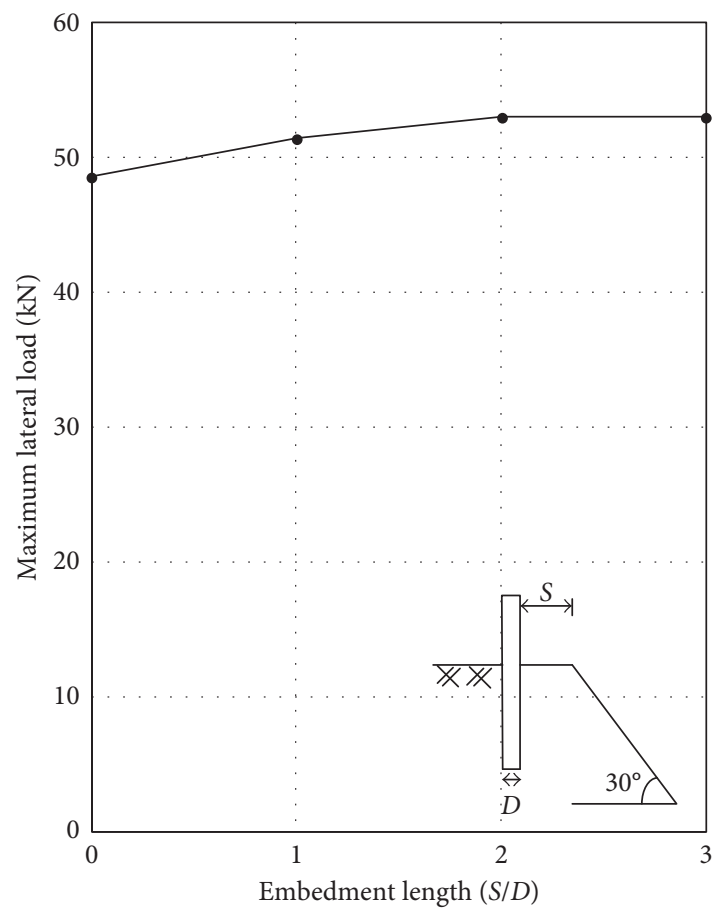

Figure 23: Variation of the maximum lateral load according to the embedment location.

experimental results for purpose of validation, which is limited to an ultimate load of quasi-static loading. It is observed in the quasi-static and dynamic loading tests that the displacements of the posts at any depth from the ground surface rise with the increase of slopes and that the ground inclination effect makes the ultimate lateral loads reduce by approximately $12-13 \%$. When the embedment length exceeds $1100 \mathrm{~mm}$, and the distance of the embedment location from the crest is greater than $S=2 D$, the responses for sloping ground are similar with those for the horizontal ground. It is also noted that the results afforded by the hybrid SPH approach give a lower lateral resistance than the 3D finite element results. This may be attributed to the large distortion effect of the node-connected soil meshes when the conventional 3D Lagrangian finite element approach is adopted. The hybrid SPH model can eliminate the degradation of the mesh occurred by the hourglass mode that produces spurious energies in numerical analysis. For the dynamics loading cases, this study does not have validation of the hybrid SPH model because of lack of experimental results. Also, in order to more generalize these conclusions, a lot of experimental data for a single guardrail post subjected to static and dynamic loading are required according to type of soils, inclination angle of ground, embedment length, and embedment of location of the posts.

\section{Data Availability}

The data used to support the findings of this study are available from the corresponding author upon request.

\section{Conflicts of Interest}

The authors declare that there are no conflicts of interest regarding the publication of this paper.

\section{Acknowledgments}

This work was supported by the Basic Science Research Program through the National Research Foundation of Korea (NRF) funded by the Ministry of Education (NRF2015R1D1A1A01060909).

\section{References}

[1] A. Tabiei and J. Wu, "Roadmap for crashworthiness finite element simulation of roadside safety structures," Finite Elements in Analysis and Design, vol. 34, no. 2, pp. 145-157, 2000.

[2] A. O. Atahan and O. F. Cansiz, "Impact analysis of a vertical flared back bridge-to-guardrail transition structure using simulation," Finite Elements in Analysis and Design, vol. 41, no. 4, pp. 371-396, 2005.

[3] L. C. Reese, W. R. Cox, and F. D. Koop, "Analysis of laterally loaded piles in sand," in Proceedings of the Sixth Offshore Technology Conference, Houston, TX, USA, May 1974.

[4] L. C. Reese and R. C. Welch, "Lateral loading of deep foundations in stiff clay," Journal of the Geotechnical Engineering Division, vol. 101, no. 7, pp. 633-649, 1975.

[5] S. Prakash and S. Kumar, "Nonlinear lateral pile deflection prediction in sands," Journal of Geotechnical Engineering, vol. 122, no. 2, pp. 130-138, 1996.

[6] D. W. Lee, J. S. Ahn, and K. S. Woo, "Vehicle impact analysis of flexible barriers supported by different shaped posts in sloping ground," Advances in Mechanical Engineering, vol. 6, article 705629, pp. 1-8, 2014.

[7] M. Borovinsek, M. Vesenjak, M. Ulbin, and Z. Ren, "Simulation of crash tests for high containment levels of road safety 
barriers," Engineering Failure Analysis, vol. 14, no. 8, pp. 1711-1718, 2007.

[8] W. Wu and R. Thomson, "A study of the interaction between a guardrail post and soil during quasi-static and dynamic loading," International Journal of Impact Engineering, vol. 34, no. 5, pp. 883-898, 2007.

[9] N. M. Sheikh, A. Y. Abu-Odeh, and R. P. Bligh, "Finite element modeling and validation of guardrail steel post deflecting in soil at varying embedment depths," in Proceedings of the Eleventh International LS-DYNA User's Conference, pp. 21-36, Detroit, USA, June, 2010.

[10] V. Nastasescu, "SPH method in applied mechanics," UPB Scientific Bulletin, Series D: Mechanical Engineering, vol. 72, no. 4, pp. 13-20, 2010.

[11] Z. Wang, Y. Lu, and C. Bai, "Numerical simulation of explosion-induced soil liquefaction and its effect on surface structures," Finite Elements in Analysis and Design, vol. 47, no. 9, pp. 1079-1090, 2011.

[12] LSTC, LS-DYNA Keyword User's Manual (Version 971 R6.0.0), Livermore Software Technology Corporation, Livermore, CA, USA, 2012.

[13] B. A. Lewis, Manual for LS-DYNA Soil Material Model 147, FHWA-HRT-04-095, APTEK, Colorado Springs, CO, USA, 2004.

[14] R. F. Kulak and L. Schwer, "Effect of soil material models on SPH simulations for soil-structure interaction," in Proceedings of the 12th International LS-DYNA Uses Conference, FSI/ALE, pp. 1-19, Detroit, MI, USA, June 2012.

[15] Y. Yoshida, I. Motonori, and T. Kokusho, "Empirical formulas of SPT blow-counts for gravelly soils," in Proceedings of the First International Symposium on Penetration Testing, pp. 381-387, Orlando, FL, USA, March 1988.

[16] L. B. Lucy, "A numerical approach of the testing of the fission hypothesis," Astronomical Journal, vol. 82, no. 12, pp. 10131024, 1977.

[17] R. A. Gingold and J. J. Monaghan, "Smoothed particle hydrodynamics-theory and application to non-spherical stars," Monthly Notices of the Royal Astronomical Society, vol. 181, no. 3, pp. 375-389, 1977.

[18] M. B. Liu and G. R. Liu, "Smoothed particle hydrodynamics (SPH): an overview and recent developments," Archives of Computational Methods in Engineering, vol. 17, no. 1, pp. 25-76, 2010. 


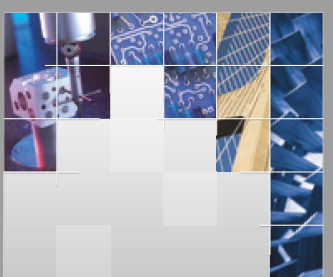

\section{Enfincering}
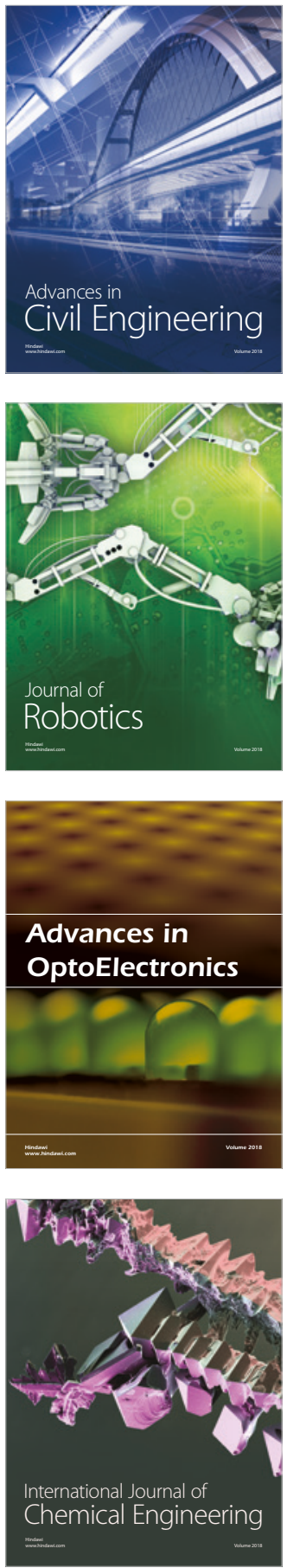

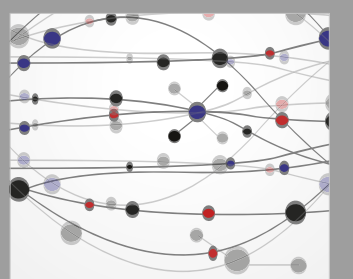

\section{Rotating \\ Machinery}

The Scientific World Journal

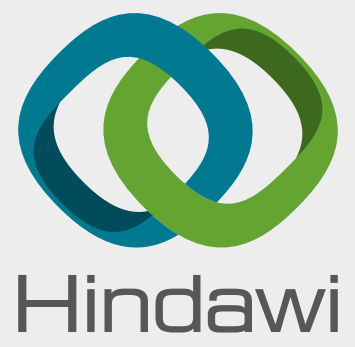

Submit your manuscripts at

www.hindawi.com
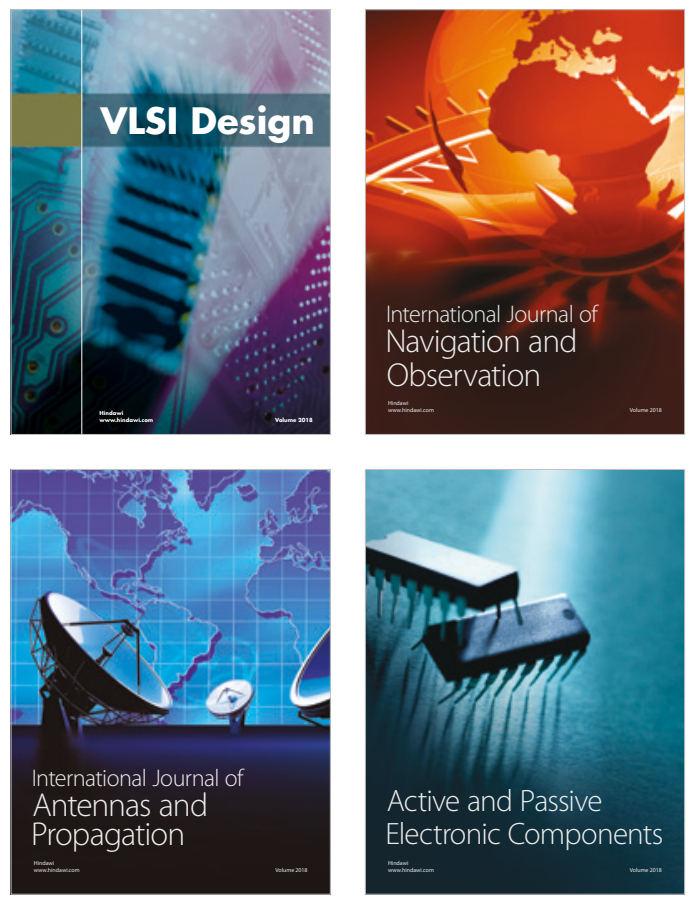
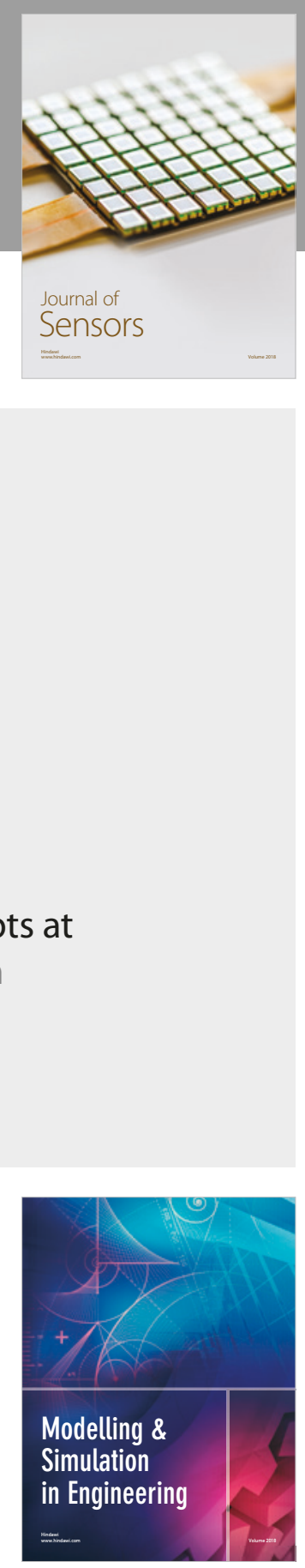

\section{Advances \\ Multimedia}
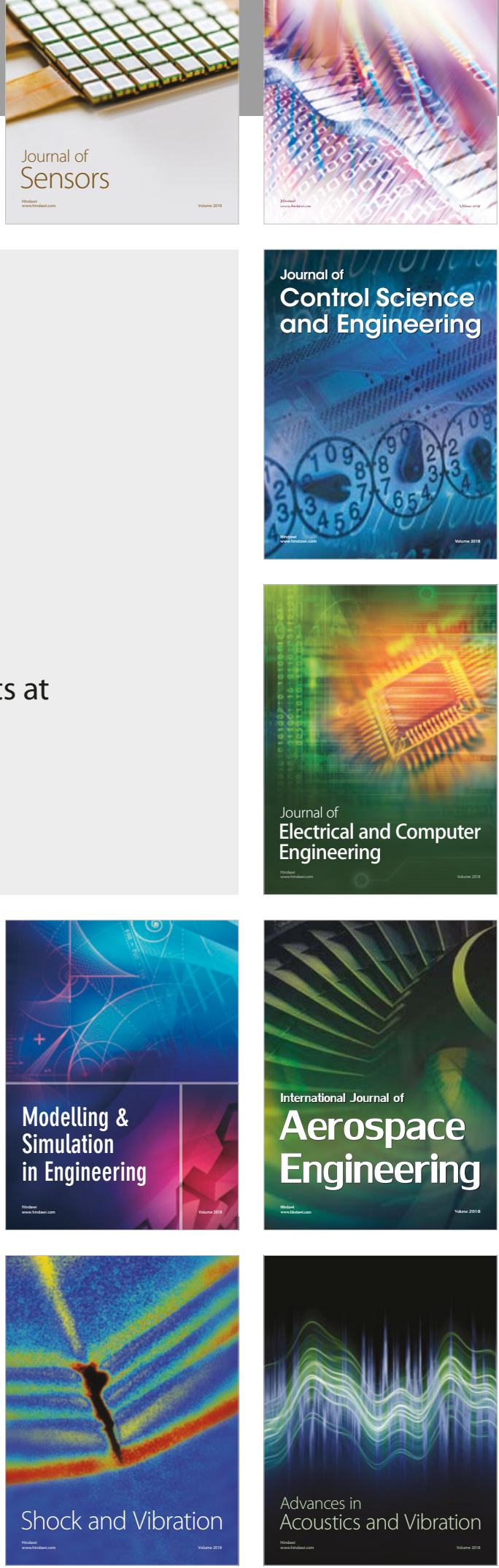